\title{
La infoxicación como causa probable de la pérdida del autoconocimiento y del eclipse del «yo»
}

\section{Infoxication as a probable cause of the loss of self-knowledge and the eclipse of the «Self»}

\section{RESUMEN:}

En el presente estudio partimos de la pregunta por los efectos, en la vida personal, de la utilización generalizada de las nuevas tecnologías, de la exposición permanente a la conexión en red y de la recepción masiva de información. Fundamentados en el modelo antropológico de Zubiri, tratamos de precisar en qué pueden consistir estos efectos. A continuación, trataremos de mostrar si la infoxicación (consistente en aturdimiento interior por sobreexposición a información y mensajes virtuales, efecto de la exposición al exceso de imágenes y de la conectividad constante del individuo en redes sociales) puede ser una de las principales causas del eclipse del yo y de la interioridad, de la mutación del yo hacia su disolución espiritual y su dispersión en la exterioridad social, política y cultural. Finalmente, trataremos de esbozar una posible vía de resistencia y de antídoto ante tal situación en la experiencia del silencio.

\section{PALABRAS CLAVE:}

Infoxicación; Yo; Autoconocimiento; Cultura; Silencio.

\begin{abstract}
:
In this article we will investigate infoxication (the effect of exposure to excess of images and to the constant connectivity of the individual in social networks) as the primary cause of the loss of interiority, introspection and the consequent mutation of oneself towards its spiritual dilution and dispersion in the social, political and cultural exteriority. Based on the anthropological model of Zubiri, we will try to specify what these effects may consist of. Finally, we will present silence and disconnection as a possible way of resistance and antidote to the loss of self-knowledge and reflection.
\end{abstract}

\section{KEY WORDS:}

Infoxication; Self; Self knowledge; Culture; Silence.

\section{Introducción}

En nuestra cotidianeidad cultural parecen lejanas las experiencias de introspección y la revisión interior del alma semejantes a las que Agustín de Hipona nos muestra como 
necesaria para el camino a lo superior: «Noli foras ire. In teipsum redi. In interiore homine hábitat veritas» (San Agustín, 1975: 141).

Parecería definitivamente periclitado el lema socrático «conócete a ti mismo», a través del cual el filósofo ateniense pretendía que toda persona buscase la verdad partiendo del estudio de su interior y en diálogo con los demás.

Hoy, por el contrario, se lleva a cabo la exaltación del yo, pero no un yo íntimo y en continua apertura y búsqueda de la verdad, sino de un yo narcisista, cosificado, espectacularizado y enmascarado, disfrazado a través de un «perfil» que se exhibe pública e impúdicamente. Así, afirma Perniola, que

Nuestra propia imagen ha dejado de pertenecernos por entero, pero además la sentimos de un modo que nos parece extraño o, por decirlo así, prefijado. Si para el narcisista el mundo es un espejo en el que se mira a sí mismo, la experiencia de lo ya sentido es como volverse el espejo donde se mira el mundo (Perniola, 2008: 36).

En el presente estudio trataremos de desentrañar si es razonable mantener esta hipótesis, la de la pérdida del sentido y experiencia de la interioridad y la consiguiente mutación del yo.

Para ello, mostraremos, en primer lugar, los efectos que desde la neurociencia se aportan respecto de la exposición masiva en el "yo» a las nuevas tecnologías y al ámbito de lo virtual. En segundo lugar, trataremos de fundamentar qué entendemos por «yo» y cuál puede ser, desde esta perspectiva antropológica, la razón de los efectos de lo que han aportado dichos neurocientíficos.

En tercer lugar, trataremos de contrastar si la infoxicación (efecto de la exposición al exceso de imágenes, la conectividad constante del individuo en redes sociales, consistente en aturdimiento interior por sobreexposición a información y mensajes virtuales) pueda ser la causa primera de dicha mutación del yo y de la imposibilidad del autoconocimiento y de la introspección.

En cuarto lugar, trataremos de mostrar cómo la infoxicación va acompañada y cataliza la monoforma (procedimiento narrativo generalizado - en tv, cine, internet...- consistente en un discurrir vertiginoso, comprimido y acelerado de contenidos fragmentados, llamados a provocar sorpresa y saturación constantes). La monoforma que impide la pluralidad de pensamientos y la hondura de la reflexión personal, así como da pie para la imposición de una monocultura (modelo cultural único que se impone como mentalidad dominante), trae como efecto el eclipse del sujeto cultural. A esta monocultura le sigue, a su vez, la pérdida de la capacidad del ejercicio de la libertad de los individuos, así como la corrupción del sentido mismo de la palabra libertad, todo ello como resultado de este aturdimiento de lo espiritual.

Por último, trataremos de esbozar alguna forma de resistencia a la monoforma, a la monocultura y a la infoxicación. Lo propondremos a través de la palabra pero, paradójicamente, sobre todo a través de la experiencia del silencio y del regreso a las fuentes interiores.

Para llevar a cabo la investigación propuesta, tomaremos en cuenta las aportaciones de índole psicológica, neurológica, sociológica y filosófica, de varios autores (Turkle, Spitzer, Baudrillard, Wolf, Small, Vorgan, Perniola, Weber, Sunstein, Groys, Watkins, Sartori, Carr, entre otros) que han trabajado y realizado estudios acerca de la infoxicación, para tratar de entender y relacionar sus aportaciones desde la antropología filosófica, en su modelo zubiriano. Iremos avanzando, desde esta fundamentación, en la comprensión del fenómeno de la infoxicación como una de las posibles causas de los efectos antropológicos, culturales y so- 
ciales de lo previamente constatado. Finalmente, abrimos a modo de hipótesis un camino que parece el que permite la resistencia y la liberación del yo diluido en este contexto infoxicante.

\section{2. ¿Eclipse del yo en la era de la comunicación digital?}

Ante la presencia inundatoria en nuestras vidas de la información masiva, la conectividad digital permanente y la exposición continua a la red, parece razonable preguntarse si estos eventos y otros semejantes tienen alguna influencia en la persona, en su subjetividad y, más en concreto, en la relación de la persona consigo misma y en el acceso a su interioridad. Para tratar de desentrañar si tiene algún efecto personal, resulta conveniente tomar nota de lo que nos dicen algunos de los más destacados investigadores en el ámbito de la neurociencia en los últimos diez años.

Resulta, en primer lugar, llamativa la aportación de Maryanne Wolf, neurocientífica cognitiva de la Universidad de Tufts (Massachusetts), quien afirma en su reciente Lector, vuelve a casa (Wolf, 2020) que tanta información y ofrecida a tal rapidez impide la comprensión de los contenidos y, sobre todo, el razonamiento pausado, ya que no permite que la memoria a corto plazo sedimente sus recuerdos. Por eso, los circuitos neuronales, que sabemos que se afinan leyendo libros y pensando sobre su contenido, tienden a empobrecerse a medida que la gente utiliza cada vez más los ordenadores, las tablets y los móviles, dificultado la comprensión y la autocomprensión que sí son favorecidas por la lectura lineal tradicional.

En realidad, se han multiplicado los estudios que constatan cambios neuronales y psicológicos en relación con la lectura, la adquisición de información y el uso de la memoria de trabajo (o a corto plazo). Los más destacables son recogidos por Manfred Spitzer, director del Centro de Transferencia de Conocimientos para las Neurociencias y el Aprendizaje en Alemania que, en su libro Demencia Digital (Spitzer, 2013), justifica y demuestra con rigor que el uso permanente de ordenadores no fomenta la formación de niños y adolescentes, sino que más bien la pueden dificultar. Por su parte, el uso de las redes sociales conduce a los jóvenes al aislamiento social y a contactos superficiales... tornándoles solitarios e infelices (Spitzer, 2013: 24-25, 109ss.). Basado en el informe PISA y en otros, vincula el uso de ordenadores con el fracaso escolar. Así mismo, afirma que las nuevas tecnologías permiten y favorecen la multitarea (Spitzer, 2013: 223ss.), lo que afecta una disminución de la serotonina y el GABA, lo que se traduce en un menor rendimiento, en baja atención y un mayor estrés. Estudiar, contestar WhatsApps, consultar el correo electrónico, jugar en línea y contestar el teléfono y escuchar música de modo simultáneo resulta estresante. Y, sobre todo, supone un obstáculo grave para la autopercepción y la autoconciencia.

En el conocido ensayo El cerebro digital (Small y Vorgan, 2009), los neurólogos estadounidenses G. Small. y G. Vorgan exponen y argumentan que las nuevas tecnologías están trayendo una serie de cambios radicales en las funciones cerebrales, lo que puede traer consigo algunas ventajas, como por ejemplo nuevas formas de interpretar la información, pero también han propiciado algunos problemas nuevos: aumento del trastorno por déficit de atención e hiperactividad (porque no favorecen la fijación de la atención en ningún contenido durante mucho tiempo), aislamiento social (aumenta la dificultad de la comunicación interpersonal directa) e 
incluso adicción (que es se desarrolla cerebralmente de la misma manera que las drogadicciones). Todos estos efectos son incompatibles con un acceso de la persona a su interioridad.

Aún más contundente, Sherry Turkle, profesora del Instituto de Tecnología de Massachusetts, e investigadora del efecto de las nuevas tecnologías en la mente, demuestra en su obra En defensa de la conversación (Turkle, 2017) que las nuevas tecnologías, que traen consigo hiperconectividad, impiden el aburrimiento, el silencio y la soledad que son la base del desarrollo de la imaginación, de virtudes como la paciencia y, en general, del desarrollo espiritual. El uso masivo de las nuevas tecnologías y la hiperconectividad tienen como efecto la atrofia de la actividad del tálamo e hipotálamo y, sobre todo, del sistema límbico, lo que trae consigo la disminución de la empatía, por no tener frente a la persona con quien se comunica y, por tanto, redunda en un empobrecimiento del autoconocimiento y de las condiciones para el mismo.

En este mismo sentido, el periodista científico Nicholas Carr en Superficiales (Carr, 2011), analiza cómo los cambios de hábitos de la sociedad digital han traído consigo una disminución de la paciencia, de la capacidad de reflexión y de la contemplación. Para Carr, la cacofonía de estímulos proveniente de Internet ha hecho aumentar la lectura insustancial, el pensamiento rápido y distraído y el aprendizaje superficial, en contraste con la era del libro en la que las personas eran animadas a ser contemplativas e imaginativas.

Basten estas referencias para constatar lo que intuíamos: se está produciendo, propiciado por el uso indiscriminado de las nuevas tecnologías y por una recepción masiva y multicanal de información, un auténtico aturdimiento cognitivo y una situación de bloqueo, por ruido mediático e informático, de la autopercepción del sujeto, de la persona, reducido en parte a ser la terminal, siempre abierta y dispuesta, de una red interminable de conectividad. A la vista de todo ello, no parece absurdo plantear la hipótesis de un eclipse del "yo" ante sí mismo por aturdimiento, por dificultad para el ejercicio de la introspección. Sin embargo, para justificar este extremo con rigor, es necesario precisar qué entendemos por «yo». Lo haremos desde la antropología filosófica de Xavier Zubiri.

\section{Qué es el «yo» y en qué consiste su afección por razones digitales}

Xavier Zubiri, al igual que la mayor parte de los filósofos personalistas y dialógicos de raíz judeo-cristiana, muestra que, frente a las cosas, cuyas esencias están clausuradas en sí, la persona se da cuenta de que existe la realidad y se da cuenta de sí mismo como realidad. Por ello decimos que la persona está abierta: se da cuenta de sí como realidad y de lo real. Sus características ontológicas que le permiten ser suyo,

determinan el enfrentamiento radical del hombre con las cosas como reales, porque constituyen un tipo radicalmente nuevo de sustantividad: la sustantividad abierta. La realidad humana es un constructo psico-orgánico organizado, solidario y corpóreo, que en su misma organización, solidaridad y corporeidad es un constructo abierto (Zubiri, 1986: 65).

Y no sólo se da cuenta de sí y de todo ello, sino que está volcado y vertido hacia la realidad. Pero el dato radical «no es apertura a otra realidad, sino apertura a la propia realidad humana en 
cuanto realidad» (Zubiri, 1986: 69). El hombre se da cuenta de sí, tiene conciencia de sí. Justo esto es lo que le permite realizar su vida, su ser moral, hacer proyectos (Zubiri, 1986: 607ss.).

Ser abierto consiste, por tanto, en que se comporta en vista de su propio carácter de realidad: Que la persona tenga una esencia abierta se refiere, por tanto, a que se trata de «esencias inteligentes y volentes» (Zubiri, 1985: 500). Esto nos ofrece un aspecto clave en nuestra investigación: esta apertura se realiza como tal intelectivamente, es decir, aprehendiendo lo real y a sí mismo como realidad. Se trata de un acto intelectivo: «Lo que constituye la apertura de esta esencia intelectiva que es el hombre...es (...) el hallarse vertida desde sí misma, en tanto que inteligencia, al sentir; esto es, la apertura es impresión» (Zubiri, 1985: 506).

Toda su actividad psico-orgánica se basa en esta condición y su actuar, se reafirma a sí frente a sí mismo y frente a los demás, se afirma como «yo». El «yo», por tanto, es el modo de ser propio de cada persona actuando desde la conciencia de sí y de lo real (Zubiri, 1986: 159), es lo que hace cada uno al dar forma a su personalidad al actuar. Por eso «el yo es la actualidad de mi forma personal en el mundo» (Zubiri, 1986: 160).

En conclusión, por ser intelectivo, esta autoafirmación del yo se hace, empíricamente hablando, desde su conciencia de sí. Todo lo que dificulte empíricamente ejercer su intelección, la aprehensión de la realidad y de su propia realidad, implica un eclipse del yo y, por tanto, un malograr su realización en tanto que persona. Si el uso indiscriminado de las nuevas tecnologías y la inundación acrítica de información producen aturdimiento cognitivo, parece que pueden suponer un eclipse del «yo», una cierta enajenación, cuyos efectos serían, entre otros, el de una infirmación personal (Domínguez Prieto, 2011: 271ss.).

Sin embargo, la comprensión de esto exige, siquiera sucintamente, tener en cuenta los tres modos de intelección que propone Zubiri. En todo proceso de conocimiento se dan estos tres niveles: por el primero, me doy cuenta de que está ante mí algo real. Es lo propio de la inteligencia sentiente (Zubiri, 1981). Por el segundo, me doy cuenta de lo que es respecto de otras cosas: es el conocimiento que Zubiri denomina «logos» (Zubiri, 1982). Por el tercero voy al fondo de lo real para saber qué es esa cosa más allá de lo que captan mis sentidos: es la «razón» (Zubiri, 1983). Es en la razón donde se pone en marcha el pensar más allá de lo dado, un pensar activado por la cosa misma que se hace presente para tratar de encontrar qué es en el fondo, cuál es su fundamento. Y esta toma de distancia, esta búsqueda del fundamento parece ser lo que queda inhabilitado por el aturdimiento cognitivo, por el exceso de información acrítica, pues -como vimos - esta inundación de imágenes, sonidos y datos deja a la inteligencia anclada en lo inmediato. Lo que queda inhabilitado, pues, es el conocer y el autoconocerse. $Y$ es que tener información (propia de la inteligencia sentiente y del logos) no supone tener conocimiento. Resulta un error craso su identificación.

\section{El eclipse del acceso del yo a su intimidad y su mutación en la era de la comunicación digital}

Veamos el eclipse del yo desde otra perspectiva complementaria. Bloqueado o dificultado el acceso del yo por dispersión de la atención en multitud de informaciones y conexiones, 
parece que termina por autoidentificarse con su autorrepresentación en las redes sociales, en las imágenes y en la conciencia cibernética de los demás. Parece socialmente eclipsado -e incluso incomprensible para la mayoría - el entender la propia identidad como una realidad in fieri desde una vocación captada en el interior para ser sustituida por un perfil en las redes. El falso yo, mero constructo ad hoc en función de su uso como terminal de la red, enmascara y eclipsa el ser auténtico, se apodera de uno mismo hasta que la propia vida se convierte en un puro espectáculo mediático que acaba por anular la autenticidad de la persona, en una terminal de redes interminables (Baudrillard, 1997: 9-23). La apariencia que moldea a la persona en la era de las redes sociales y el exceso de imágenes, "no se deriva de la interiorización, sino del reflejo de entes externos» (Perniola, 2008: 36).

Por eso, se constata socialmente que la presentación a los demás del yo, e incluso a uno mismo, está siendo transformada por la digitalización de la vida hasta tal punto que la exterioridad se convierte para algunas personas (youtubers, instagramers, etc.), en su única interioridad reconocida. El papa Francisco advierte, en este sentido, que la comunicación está siendo confundida con el contacto virtual:

\begin{abstract}
La web y las redes sociales han creado una nueva manera de comunicarse y de vincularse [...] Pero no es sano confundir la comunicación con el mero contacto virtual. De hecho, el ambiente digital también es un territorio de soledad, manipulación, explotación y violencia, hasta llegar al extremo de la dark web. Los medios de comunicación digitales pueden exponer al riesgo de dependencia, de aislamiento y de progresiva pérdida de contacto con la realidad concreta, obstaculizando el desarrollo de relaciones interpersonales auténticas (Francisco, 2019: 49).
\end{abstract}

A través de las redes sociales, el yo pasa a ser un espectáculo, un mero show que se conforma a través de las peticiones, exigencias y comentarios de los demás. El nuevo mensaje de la comunicación en redes es uno mismo (Perniola, 2011). Es decir, el transmisor se convierte en mensaje. Se disipa la separación entre lo público y lo privado, convirtiendo a lo privado en mero espacio público digital (estados de Whatsapp, stories de Instagram, imágenes de Snapchat, hauls y umboxing en YouTube, etc.).

De modo paradigmático podemos comprobar esto en el ámbito político, en el que constatamos la retransmisión constante de la vida del político como espectáculo y noticia, con el riesgo de que se convierta en mero comediante y que le «preocupe solo la impresión que su imagen hace" (Weber, 1981: 156). Ya no nos encontramos con los grandes discursos políticos con intenso contenido, sino que ahora nos encontramos con el espectáculo mediático en torno a la vida del representante político: «La vida política actual es espectáculo de meras imágenes que, con ser nada más que eso, atraen, fascinan y generan culto de la personalidad que, en realidad, es un culto de la imagen de la personalidad» (López Aranguren, 1988: 94).

Pero esto, que se da por eminencia en el ámbito político, en el de las crónicas de sociedad y en los reality shows, lo vemos reproducido en la vida cotidiana. Se trata de la constante retransmisión de la vida propia y de la de los vecinos, de la propia privacidad y cotidianidad convertida en espectáculo (Sunstein, 2007). Esto supone la pérdida del yo como ese espacio propio e íntimo como ámbito de lo interior, permitiendo la aparición de un falso «yo» sujeto 
a la instantaneidad y la inmediatez. Todos han de saber dónde estoy, qué hago, con quién estoy... en cada momento, en vivo y en directo.

La intimidad es algo que ya no se guarda, sino que se expone con pretensión de espectacularidad. Se trata de una mutación del yo que ya no vive en la realidad misma, sino en un mundo generado a partir de la imagen subjetiva instantánea, del culto al «perfil». Ni quisiera cabe ya la verdadera ficción. Estamos en una época de crisis de la ficción (Perniola, 2011), pues interesan más los «yoes reales» que los personajes de ficción. Así se forja un imperio, no solo en redes sociales, sino también en televisión, que gira en torno a la vida -espectacularizada - de ciertas personas que son sometidas a presiones y momentos que son escogidos por la audiencia y no desde su propia libertad.

Por tanto, el nuevo «sujeto digital» conforma su propia identidad como mero mensaje que se transmite a un público que va moldeando dicha imagen. Ya no es la presencia de la persona ante el mundo que afirmaba Zubiri, sino un constructo que se muestra impúdicamente como espectáculo público. El yo no es quien es, sino lo que los demás solicitan de él:

El Narciso contemporáneo no puede estar tan seguro de su propio gusto. Hoy en día somos incapaces de gustarnos a nosotros mismos si no somos del gusto de la sociedad en la que vivimos; $y$ en nuestra sociedad tenemos que ser activos si queremos ser objeto de la admiración de los demás (Groys, 2017).

Consecuentemente, los problemas que se ofrecen al homo videns, transformación del homo sapiens hacia un homo para el cual «la palabra está destronada por la imagen y todo acaba siendo visualizado» (Sartori, 2012: 11), ya no son los grandes problemas filosóficos personales e históricos (la vida, la muerte, el conocimiento, etc.), sino que son la tematización acrítica de todos aquellos impulsos que rodean al culto a la personalidad: cómo conseguir más followers, cómo lograr más visualizaciones de mis imágenes, cómo alcanzar un mayor número de «me gusta», etc. Esta faceta se desarrolla hasta tal punto que se convierte en una nueva esclavitud, la del culto a la propia imagen (que ahora sustituye a la personalidad y al yo). Se convierte en una adicción real que las propias redes sociales explotan y fomentan (Chóliz Montañés, 2016) de cara a su beneficio empresarial.

Otra de las características de la formación de esa nueva identidad virtual, alejada del yo real al que la persona aspira y debe construir desde dentro, es el miedo y el pánico a la soledad (de ahí nuevas psicopatologías como la «nomofobia»: no-mobil-phone-phobia). La soledad buscada y el silencio practicado a diario implican pensamiento, oración, introspección, autoconocimiento, crecimiento personal... Sin embargo, todas estas características no pueden florecer ya que no se ponen en práctica por el pánico a la soledad y la necesidad constante de conexión. El yo que se construye únicamente en el reflejo mediático de los demás, no puede dejar de estar permanentemente en contacto virtual con los espectadores que le conforman (Groys, 2017). El pánico a la soledad se convierte en constante y evita el autodescubrimiento, el silencio y la búsqueda interior de la verdad, del bien y la belleza que nos constituyen.

Recordemos que la antropología filosófica de Zubiri muestra cómo el hombre es el autor de su vida porque su vida es suya, su realidad es propia y tiene que realizarla (Zubiri, 1988: 48). Sin embargo, empíricamente constatamos que en las actuales circunstancias el "yo" desdibuja su autopertenencia y termina por convertirse en espectador de su propia marca personal, de su propia historia mediática, de su fábula que ha de vender grabándose, foto- 
grafiándose y exponiéndose permanentemente. Una exposición que no parte del diálogo y la conversación (Turkle, 2017), sino de las meras impresiones virtuales.

Hemos de aclarar que cuando hablamos de la formación de un nuevo yo que ya no se pertenece o que ya no es más que pura exterioridad, no nos referimos a que deja de ser persona o que ya no pueda, si lo busca y cambia, descubrirse a sí mismo; sino que hablamos de la personalidad, del ethos, de la conformación social del individuo.

A la vista de todo lo propuesto, ¿podemos señalar alguna causa de esta mutación del yo y de este eclipse de la interioridad?

\title{
5. La infoxicación, la inmediatez y exceso de imágenes en redes sociales como una de las posibles causas de la pérdida de la experiencia y del autoconocimiento
}

El mundo digital, como hemos justificado en los epígrafes anteriores, propicia que la persona quede incrustada en la inmediatez, en la constante recepción de imágenes e información a través de redes sociales, de la incesante recepción de datos a través de mensajes cortos, de la multitarea... Se trata del fenómeno que hoy se denomina infoxicación:

\begin{abstract}
El tema de la sobrecarga informativa se ha abordado de forma cuantiosa desde hace años, puesto que es uno de los procesos más evidentes de nuestro tiempo, especialmente desde la incorporación de Internet a la vida cotidiana. Este crecimiento exponencial de información que intoxica a los ciudadanos, Alfons Cornellá lo denominó, en 1996, como «infoxicación»y, desde entonces, diversos autores de diferentes disciplinas lo han utilizado para explicar sus efectos en la población, tanto a nivel del individuo, como a nivel social (Casas-Mas, 2014: 3).
\end{abstract}

A través de los medios de comunicación de masas y, más recientemente, de las redes sociales, se ha producido la pérdida de la experiencia, del sentir (Perniola, 2008), hasta tal punto que ya no se observa aquello que se está viendo si no es a través de la lente del móvil con el que se está fotografiando. Ya no se tiene experiencia de lo real, ni se protagonizan las escenas, sólo se muestran ante la cámara para dejar constancia ante un público de seguidores (Sosa Plata, 2009). A esto se añade, según justificamos al exponer la antropología zubiriana, que no solo no hay experiencia de lo real y de uno mismo como realidad sino que, además, no hay conocimiento de lo real ni autoconocimiento. La infoxicación, a través de sus efectos psíquicos analizados en el primer epígrafe (déficit de atención, aturdimiento cognitivo, empobrecimiento de la memoria, imposibilidad de la reflexión, bloqueo de la imaginación...), impide el acceso a la interioridad personal.

De modo especial, internet, a través de los diversos soportes digitales que utilizamos, exige nuestra atención de manera absorbente, incita a comportamientos compulsivos en el envío continuo de mensajes y consulta de novedades, atrayendo nuestra atención para dispersarla y, finalmente, ante la cacofonía de estímulos, cortocircuitar el pensamiento reflexivo (Carr, 2011). Por otro lado, la cantidad ingente de información que se recibe permanentemente, y la velocidad con la que se cambia de fuente, de pantalla, de vínculo, impide a la 
memoria a largo plazo sedimentar ningún concepto o esquema conceptual, dando lugar a una «sobrecarga cognitiva» (Carr, 2011: 155).

Todo ello, definitivamente, supone la pérdida de la experiencia de la soledad, de la intimidad, de uno mismo, del autoconocimiento... Nos preocupa tanto el compartir que dejamos de lado el sentir (Perniola, 2008), la reflexión y la realidad. La mayor pérdida que se produce por el exceso de imágenes y la infoxicación, es la pérdida del autoconocimiento y de la introspección, pero también la incapacidad para formular las preguntas últimas y el acceso a la ultimidad de lo real.

El autoconocimiento y la introspección requieren reposo, toma de distancia de uno mismo y de la realidad sensible, repensar la experiencia propia, la reflexión sobre sí y sobre lo que se presenta ante nosotros como importante:

No basta la experiencia: hay que reflexionar sobre ella. Prueba de ello es que las personas con más experiencias no suelen coincidir con las personas con más madurez. Sólo reflexionando sobre mi propia vida puedo llegar a conocerme y madurar (Domínguez Prieto, 2002: 33)

Para el autoconocimiento y la preservación de la intimidad, se requiere una profundidad de la conciencia. Precisamente, a esta solo se llega mediante la reflexión, la lectura, la meditación y la pausa interior; elementos que hoy son eliminados y cambiados por la inmediatez, la velocidad, la conectividad permanente, las imágenes constantes, las falsas necesidades de consumo, etc. La oración, la lectura, la meditación o la reflexión, en cambio, requieren silencio, pausa, concentración... todo aquello que se trata de evitar mediante el abuso de los aparatos digitales, de las redes sociales y de los usos sociales ligados a los mismos (Hilt, 2019).

La atención del homo videns es reconducida para que en ella no quepa el razonamiento extenso, sino que se dirija constantemente a pequeños mensajes vacíos que no requieren de profunda reflexión ni interiorización. «Existe relación significativa entre la dependencia del móvil, los hábitos y actitudes hacia la lectura con el rendimiento académico de los estudiantes» (Hilt, 2019: 108).

En este contexto cada vez es más difícil la concentración y la posibilidad de acceder a uno mismo. Sin hábito de silencio, de reflexión profunda y de interiorización, difícil resulta que en el mundo actual no se produzca una mutación del yo hacia su mera exteriorización.

Finalmente, digamos que toda la persona se ve afectada: el intelecto queda aturdido por el exceso acrítico de información. La afectividad pierde capacidad de reacción ante la constante muestra de imágenes que la ciegan paulatinamente, mediante la espectacularización de las realidades humanas que más nos afectan (Gómez Granados, 2007).

Intelecto y afectividad quedan reducidos en su capacidad de comprensión y reacción ante el bombardeo de imágenes y de información que llega sin pausa a la persona, dado que «la afectividad es la capacidad personal de ser modificado interiormente por una realidad presente» (Domínguez Prieto, 2002: 61).

Finalmente, ante la ausencia de fines en el intelecto y la «sentimentalización» del afecto, la voluntad misma queda debilitada. 
Y, sobre todo, la persona queda expulsada de su interioridad más honda, de su dimensión espiritual, del ámbito de las creencias, esperanzas y amores.

\section{Impacto social y político de la infoxicación: imposición del paradigma único}

La infoxicación, que lleva a la mutación y eclipse del yo, tiene su trasunto en al ámbito social y político. Podemos dar cuenta de ello si descubrimos que la infoxicación ha sido un catalizador de la monoforma, es decir, de un único formato de comunicación (y de cultura) que coarta la pluralidad de formatos, expresiones y culturas. La monoforma supone la imposición de un paradigma de comunicación reducido que termina por calar en la forma de auto-representación de los individuos. Por ello, la monoforma cultural, social y política se ha fortalecido con el incremento de medios de transmisión de información por red.

El profesor Watkins (2017) relata de la siguiente manera el descubrimiento que hizo, junto a sus alumnos, de la monoforma en los medios de comunicación:

Fue así, gracias al análisis de la forma narrativa utilizada por la televisión (telediarios y series de ficción, como Raíces u Holocausto), como aquellos estudiantes y yo descubrimos el uso estandarizado de la Monoforma (que es como dimos en llamarla). No solo contabilizábamos el número de cortes (de montaje) que había en cada noticia y cuántas veces cambiaba la cámara de perspectiva dentro de un mismo plano (zooms, panorámicas, basculaciones, etcétera), sino que también examinábamos el tiempo de emisión concedido a las opiniones del público frente al concedido a los presentadores, así como los momentos de silencio. Nos sorprendió la increíble velocidad, pero también la repetición y la uniformidad en la sucesión de imágenes (montaje). Con independencia del tema tratado, del formato en el que se presentara (telediario o ficción televisiva) y del contenido emocional e intelectual, la estructuración del tiempo y el espacio era idéntica (p. 20).

Así, la monoforma trata de legitimar la explotación del entretenimiento, impide los debates críticos y trata de estandarizar la forma narrativa (Watkins, 2017). Mediante el uso de una gran velocidad a la hora de presentar las imágenes y un tiempo muy reducido, el espectador no es capaz de reflexionar ni de repensar la forma de aquello que ha visto. Confluye, plenamente, con todos los medios en los que se promueve la avalancha embrutecedora de imágenes y datos, de informaciones y sonidos, de suscitaciones y eslóganes, que terminan por expulsar al yo de su relieve personal, de su personalidad y su identidad propia. La monoforma es «infoxicadora» por naturaleza.

Prueba de ello es la facilidad con la que, a través de la forma única, se lleva a los espectadores-internautas al fácil sentimentalismo ante temas que deberían ser de profunda y densa reflexión. ¿No parecen basarse, cada vez más, las interminables campañas políticas y, en general, los mensajes de los políticos, en eslóganes simples que fungen como nueva cosmovisión? El efecto de ello es que muchos ya no votan teniendo en cuenta el programa electoral de un partido, sino impulsivamente a partir del slogan o del candidato que más éxito comunicativo ha tenido durante la campaña. Por ello, «la política actual 
busca conquistar mediante la persuasión alienante» (López Aranguren, 1988: 93) y da lugar a que la mayoría de los partidos políticos gasten una mayor cantidad de dinero en el marketing digital electoral, que en la elaboración de un programa coherente y bien estudiado (Lucas Postigo, 2012).

¿Y no se termina presentando como normal - a través de plataformas de películas, series, diarios televisados, etc. - una única forma axiológica que impide todo intercambio crítico de pensamiento? Lo impide por la forma sentimental en que se presenta, pero también por su lanzamiento infoxicador. En definitiva, se trata de «agredir y atrapar al público a través de una programación uniforme, en la que no hay posibilidad de elección; una programación basada en los formatos más superficiales, ramplones y comerciales» (Watkins, 2017: 42).

Este modo de informar mal y de manera distorsionada (Sartori, 2012) que se presenta como único, también impide la formación del yo a través de la reflexión y el encuentro íntimo con uno mismo, en la misma medida en que predispone al individuo para la espectacularización del yo y la inmediatez de la imagen (de sí) compartida en redes sociales.

De modo análogo -y en conexión con esta imposición informativa y del entretenimiento- la monoforma infoxicadora tiene su proyección en la cultura, dando lugar a la monocultura o a una cultura monodimensional. Con esto nos referimos a una forma cultural que anula la pluralidad y busca la «homogeneización» de las personas. Y esto pasa, necesariamente, por impedir la reflexión personal, la toma de posición personal. Y esto es un fenómeno extensible a todo Occidente: se trata de imponer una cultura que no se reconoce como limitada, una cultura única para todo el globo que no es crítica ni fomenta el pensamiento libre. En plena globalización, nos encontramos con una imposición cultural, política y económica del paradigma occidental a todos los pueblos del mundo (Mayorga, 2016).

Si se quiere salir de dicho paradigma, ha de recuperarse el que la cultura sea cultura crítica, esto es, analítica. De no ser así, se convierte en «cultura preparatoria para la barbarie» (Mayorga, 2016: 25). En efecto, cultura y barbarie son compatibles si la primera no es crítica y no fomenta la reflexión. Véase el ejemplo en la Alemania nazi, en la que los soldados eran capaces de ir al teatro por la mañana, escuchar música de Bach al mediodía y meter en cámaras de gas a personas por la noche.

El nuevo paradigma cultural (monocultura) parece promover una sociedad anestesiada, para lo cual ha encontrado un instrumento privilegiado en las nuevas tecnologías utilizadas de modo masivo y acrítico. Como dirá Baudrillard, primero fue Dios quien murió, luego murió el hombre y, finalmente, ha muerto la realidad a manos de lo virtual. Por eso, lo virtual se convierte «en el último predador y predador de la realidad, segregado por ella misma como una suerte de agente viral y autodestructivo» (Baudrillard, 2008: 21).

¿Dónde podemos encontrar un espacio de resistencia ante esta monoforma y monocultura infoxicadoras? ¿Dónde encontrar espacios para el autoconocimiento y la reflexión? Sin duda, esto puede ocurrir a través de la palabra escrita, a través de formas culturales como el teatro o la novela que permiten recuperar experiencias de la soledad, la intimidad, la alteridad...

A través del teatro (y poniendo a este como ejemplo de la cultura de resistencia que tiene la posibilidad de salirse de la monoforma y la infoxicación), Mayorga propone recuperar un espacio para la palabra densa y la profundidad de la misma. «Hay palabras que condenan, 
otras que salvan, otras que enamoran y otras que nos hacen llorar... ¿Qué tenemos para examinar las palabras más que las palabras mismas?» (Mayorga, 2016: 53).

Esta cultura crítica será la que fomente no la rapidez y la inmediatez, sino la palabra densa que invita a la reflexión, a la introspección del espectador o del lector, a que este se sitúe en diversos contextos y situaciones. Puede ser la palabra escrita, tal y como vimos en el primer epígrafe, la palabra dialogada en el encuentro con otro, o las experiencias personales de silencio, de reflexión, de introspección. Se trata, en todos ellos de recuperar espacios de libertad para poder volver a la interioridad.

\section{La pérdida del sentido de la libertad en el paradigma único impuesto}

La monoforma, la monocultura y el pensamiento unidimensional, traen consigo una merma en el ejercicio de la libertad, ya que esta brota de la interioridad y del autoconocimiento. «Para ejercer su libertad, cada persona reorganiza las tendencias y motivos de modo que estos serán "sus" motivos y "sus" preferencias. La libertad acontece en el dominio de sí mismo" (Domínguez Prieto, 2002). De esta manera, la merma de la posibilidad del ejercicio de la libertad surge necesariamente de la imposición, por parte de los followers y espectadores, de los motivos y las preferencias sobre lo que debe acontecer en el relato mediático de la propia vida, inmersa en las redes sociales. La anulación del dominio de uno mismo debido al yo ficticio generado meramente por las impresiones de los demás, imposibilita la práctica de la libertad.

Por otro lado, está claro que la monoforma, la multitarea, el continuo fluir de mensajes, la masa de información inasimilable y la continua incitación estimular inciden en la progresiva incapacitación para la reflexión, la libertad y el autoconocimiento de las personas. La propia palabra «libertad» es vapuleada en todos programas de los medios de comunicación de masas y, por tanto, vaciada de contenido, para ser rellenada, a placer, por aquello que convenga al orador o al político y encaje dentro de su «imagen prefabricada que sustituye a la persona real en aras de persuadir o manipular a los oyentes» (López Aranguren, 1988: 93). Continuamente se escuchan alusiones en todos los canales de comunicación a la «verdadera libertad». Pero ¿qué imagen presentan de esta? La palabra «libertad» es utilizada como talismán, vacío de contenido, para lograr manipulación de masas, mientras que la democracia no garantiza la libertad interior (López Quintás, 2008: 76-112).

Se suele acudir a la palabra libertad en referencia - errónea- al libertinaje. Desde luego, se trata de una «libertad» (del latín líber: liberar) que no fomenta mucho ese liberar a la gente de las cargas que sufren al que hace referencia la propia etimología del término. Tampoco fomenta la solidaridad en busca de unas condiciones de vida justas que permitan vivir dignamente a todos (Constant, 1989).

En definitiva, se presenta una idea de la libertad que no va ligada a la justicia. Es decir, no se defiende la libertad positiva ni negativa (Berlin, 2005) en última instancia, sino el libertinaje político y económico. Se trata de hacer ver como paradigma único de la actualidad el imponer a los demás - por medio de los canales de comunicación - una forma de pensar, de sentir, de actuar, de enseñar y hasta de vestir única, que no dé pie a la pluralidad de opiniones y al respeto a la diversidad de pensamientos. 


\section{El silencio como espacio de resistencia posibilitante del autoconocimiento y de la autenticidad personal}

Frente al eclipse de la interioridad, que hemos analizado a lo largo del texto y cuyo foco principal parte de la infoxicación, la monoforma, y la mutación o eclipse de la identidad personal en medio de imágenes, informaciones y sobre-exposición a redes sociales, nos preguntamos si existe un campo de resistencia que posibilita el autoconocimiento, la introspección y la autenticidad personal.

Tiene que ser un ámbito que permita, acorde con nuestro análisis antropológico, un espacio que permita pasar de la aprehensión de lo real, al campo de lo real y, de aquí, a la realidad profunda, al fundamento de lo real y, en lo referente a la persona, a su autoconocimiento y al acceso a su hondón espiritual.

Posiblemente este espacio pueda ser, tal y como enseñan los grandes místicos y la experiencia espiritual más cotidiana, el de la práctica buscada del silencio y la escucha, del acceso a las fuentes interiores (la meditación, la oración, la reflexión, la lectura espiritual, la contemplación...). Son elocuentes las invitaciones de los padres del desierto y, sobre todo, de los grandes místicos del Siglo de Oro al retirarse, al silencio, a los largos espacios de oración. Santa Teresa de Jesús en su Camino de perfección insiste en los modos para recoger el pensamiento (Santa Teresa de Jesús, 1986: 340ss.).

También hoy el papa Francisco (2019) recuerda cómo en medio de tanto ruido, de tanto ir y venir de datos, solo el silencio nos permite el encuentro con nosotros mismos y la posibilidad del discernimiento de nuestra vocación y proyecto vital:

\footnotetext{
Todos, pero especialmente los jóvenes, están expuestos a un zapping constante. Es posible navegar en dos o tres pantallas simultáneamente e interactuar al mismo tiempo en diferentes escenarios virtuales. Sin la sabiduría del discernimiento podemos convertirnos fácilmente en marionetas a merced de las tendencias del momento (p. 169) [...] Una expresión del discernimiento es el empeño por reconocer la propia vocación. Es una tarea que requiere espacios de soledad y silencio, porque se trata de una decisión muy personal que otros no pueden tomar por uno (p. 171).
}

La mayor forma de resistencia está en el silencio (D’Ors, 2014), en superar el debilitamiento del yo, en la autorreflexión y la escucha de la llamada y del proyecto vital. Solo a través del silencio y de la autorreflexión uno se «cae del caballo» del narcisismo y se reconoce como limitado, vulnerable y falible. A partir de ahí, del reconocimiento humilde de la propia vulnerabilidad, se comienza el autoconocimiento y la búsqueda de la verdad.

\section{Conclusiones}

La pérdida de la experiencia y el exceso de información, nos llevan a la pérdida de la escucha. Solo por medio del silencio podremos poner en práctica la escucha. Centrados en la recepción de mensajes nos olvidamos de hacer tiempo para el mensaje, para la escucha de la llamada y la búsqueda del proyecto: 
En general, absorbidos por trabajos, diversiones, salidas, ruidos, nos cuesta escuchar, darnos cuenta de lo que está ante nosotros. Solo vemos lo que esperamos ver. Pero vemos y escuchamos poco, porque estamos saturados de imágenes y ruidos. Por eso necesitamos urgentemente una terapia de silencio para sanar el oído, para volver a escuchar (Domínguez Prieto, 2016: 33).

Así pues, el silencio es hacer espacio dentro para no perderse en el bullicio de afuera. El silencio es acallar el ruido exterior para afinar el oído hacia lo interior, rompiendo con el alienante estilo de vida e infoxicación constante. Una buena forma de comenzar el silencio y la escucha es apagando el móvil y, con ello, desconectando el yo virtual que pretende reemplazar a mi yo real.

Insertos en un sistema socioeconómico que nos insiste en el consumir, el comprar y el producir sin freno, el silencio es ese espacio de no producción, de lo inútil, de lo que me permite la llegada al centro vital de mi ser (Domínguez Prieto, 2016). Solo haciendo espacio al ser conseguiremos poner freno a la imposición del tener.

Solo puedo conocerme a mí mismo y encontrarme con mi realidad y mi proyecto vital, si hago silencio y pauso el ritmo agobiante de vaivenes digitales y vitales que cortan de raíz mi conexión conmigo mismo y mi realidad más íntima. Solo mediante el silencio soy capaz de revertir la mutación del yo hacia el mero personaje mediático y recuperar mi luz propia.

Si decíamos al comienzo que la infoxicación nos lleva a una mutación del yo que deja de ser yo y se convierte en una mera creación de los deseos de los followers y espectadores; a través del silencio me librero, «caigo en la cuenta de que ya no tengo que demostrar nada a nadie. No me siento ya en la obligación de asombrar a nadie, ni de explicar lo que supongo que son mis fracasos, ni de excusarme por no ser quienes otros querían que fuese" (Domínguez Prieto, 2016: 37). Ya no he de postrarme ni rendir cuentas ante mis «personajes» sociales.

El silencio permite «la vuelta a casa», el regreso a la interioridad habitada, a las fuentes interiores. En definitiva, el silencio permite la escucha de uno mismo y no de los incesantes ruidos externos; permite romper con lo exterior y situarse frente a uno mismo (Domínguez Prieto, 2016) para redescubrirse. El silencio genera un espacio para la escucha activa del propio yo, para el autoconocimiento y la introspección. Solo desde la escucha de uno mismo podemos recuperar la autenticidad del propio ser y escuchar mis necesidades reales.

Frente a un mundo en constante movimiento que nos lleva a la mutación y degeneración del yo, el silencio nos habilita para la pausa, la escucha de uno mismo y el acceso al conocimiento del mundo, del otro y del Otro. Desde este punto de partida nuevo y reconfortante, podremos iluminarnos a nosotros y a otros, así como comunicarnos desde la autenticidad y el diálogo profundo, enriquecedor y plenificante.

\section{Bibliografía}

BAUDRILLARD, Jean (1997). El otro por sí mismo. Barcelona: Anagrama.

BAUDRILLARD, Jean (2008). El pacto de lucidez o la inteligencia del Mal. Buenos Aires: Amorrortu.

BERLIN, Isaiah (2005). Dos conceptos de libertad y otros escritos. Madrid: Alianza.

CARR, Nicholas (2011). Superficiales. Madrid: Taurus.

CASAS-MAS, Belén (2014). «Infoxicación a través de los medios de comunicación». Revista Internacional de Comunicación, (24), 1-11. 
CHÓLIZ MONTAÑÉS, Mariano (2016). «Adicción a redes sociales: conceptualización del problema, evaluación y prevención». En Odriozola, Enrique Echeburúa (Ed.). Abuso de Internet, ¿antesala para la adicción al juego de azar online? Madrid, España: Pirámide, pags. 105-130.

CONSTANT, Benjamin (1989). Escritos políticos. Madrid: CEC.

DE HIPONA, Agustín (1975). De Vera Religione. Trad. Victorino Capánaga, Madrid: Biblioteca de Autores Cristianos.

DE JESÚS, Teresa (1986). «Camino de perfección». En Efrén de la Madre de Dios y Otger Steggink (Eds.). Santa Teresa de Jesús: Obras Completas. Madrid: Biblioteca de Autores Cristianos.

DOMÍNGUEZ PRIETO, Xosé Manuel (2002). Para ser persona. Madrid: Fundación Emmanuel Mounier. DOMÍNGUEZ PRIETO, Xosé Manuel (2011). Psicología de la persona. Madrid: Palabra.

DOMÍNGUEZ PRIETO, Xosé Manuel (2016). Despierta y alégrate. Madrid: PPC.

D'ORS, Pablo (2014). Biografía del silencio. Madrid: Siruela.

FRANCISCO, Papa (2019). Exhortación Apostólica Postsinodal Christus Vivit. Salamanca: Edibesa.

GÓMEZ GRANADOS, Manuel (2007). «La violencia en los medios de comunicación: ¿realidad, espectáculo o espectáculo de la realidad?». La Cuestión Social: documentos, ensayos, comentarios y reseñas de libros acerca de lo social, 15(4), 327-339.

GROYS, Boris (2017). «Autodiseño o narcisismo productivo». Revista ARQ, (95), 140-145.

HILT, Jorge (2019). «Dependencia del celular, hábitos y actitudes hacia la lectura y su relación con el rendimiento académico». Revista de Investigación Apuntes Universitarios, 9(3), 103-116.

LÓPEZ ARANGUREN, José Luis (1988). Ética de la felicidad y otros lenguajes. Madrid: Tecnos.

LÓPEZ QUINTÁS, Alfonso (2008). La tolerancia y la manipulación. Madrid: Rialp.

LUCAS POSTIGO, Miguel Ángel (2012). «Campaña en la red: estrategias de marketing electoral en Internet». Redmarka: Revista Académica de Marketing Aplicado, 8(1), 177-199.

MAYORGA, Juan (2016). Elipses. Segovia: Ediciones La uÑa RoTa.

PERNIOLA, Mario (2008). Del sentir. Valencia: Pre-textos.

PERNIOLA, Mario (2011). La sociedad de los simulacros. Buenos Aires: Amorrortu.

SARTORI, Giovanni (2012). Homo videns: la sociedad teledirigida. Barcelona: Taurus.

SMALL, Gary y VORGAN Gigi (2009). El cerebro digital. Cómo las nuevas tecnologías están cambiando nuestra mente. Barcelona, España: Urano

SOSA PLATA, Gabriel (2009). «¿Avance o dependencia?». Revista Mexicana de Comunicación, 22(118), 16-21.

SPITZER, Manfred (2013). Demencia digital. Barcelona: Ediciones B.

SUNSTEIN, Cass (2007). Republic.com 2.0. Princeton: Princeton University Press.

TURKLE, Sherry (2017). En defensa de la conversación. Barcelona: Ático de los libros.

WATKINS, Peter (2017). La crisis de los medios. Logroño: Pepitas de calabaza.

WEBER, Max (1981). El político y el científico. Madrid: Alianza.

WOLF, Maryanne (2020). Lector, vuelve a casa. Como afecta a nuestro cerebro la lectura en pantallas. Bilbao: Deusto.

ZUBIRI, Xavier (1981). Inteligencia sentiente. Inteligencia y realidad. Madrid: Alianza.

ZUBIRI, Xavier (1982). Inteligencia y logos. Madrid: Alianza.

ZUBIRI, Xavier (1983). Inteligencia y razón. Madrid: Alianza.

ZUBIRI, Xavier (1985). Sobre la esencia. Madrid: Alianza.

ZUBIRI, Xavier (1986). Sobre el hombre. Madrid: Alianza.

ZUBIRI, Xavier (1988). El hombre y Dios. Madrid: Alianza. 